\title{
Highly Efficient Cyclic Dinucleotide Based Artificial Metalloribozymes for Enantioselective Friedel-Crafts Reactions in Water
}

\author{
Changhao Wang ,* Min Hao+, Qianqian Qi, Jingshuang Dang, Xingchen Dong, Shuting Lv, \\ Ling Xiong, Huanhuan Gao, Guoqing Jia, Yashao Chen, * Jörg S. Hartig, and Can Li
}

\begin{abstract}
The diverse secondary structures of nucleic acids are emerging as attractive chiral scaffolds to construct artificial metalloenzymes (ArMs) for enantioselective catalysis. DNAbased ArMs containing duplex and G-quadruplex scaffolds have been widely investigated, yet RNA-based ArMs are scarce. Here we report that a cyclic dinucleotide of $c$-di-AMP and $\mathrm{Cu}^{2+}$ ions assemble into an artificial metalloribozyme (cdi-AMP.C $\mathrm{Cu}^{2+}$ ) that enables catalysis of enantioselective Friedel-Crafts reactions in aqueous media with high reactivity and excellent enantioselectivity of up to $97 \%$ ee. The assembly of cdi-AMP.Cu $u^{2+}$ gives rise to a 20-fold rate acceleration compared to $\mathrm{Cu}^{2+}$ ions. Based on various biophysical techniques and density function theory (DFT) calculations, a fine coordination structure of $c-d i-A M P \cdot C u^{2+}$ metalloribozyme is suggested in which two c-di-AMP form a dimer scaffold and the $\mathrm{Cu}^{2+}$ ion is located in the center of an adenine-adenine plane through binding to two N7 nitrogen atoms and one phosphate oxygen atom.
\end{abstract}

W th ever-increasing interest for developing new-to-nature biocatalysts, much attention has been paid to rationally designed artificial metalloenzymes (ArMs) that combine the features of enzymatic catalysis and homogeneous catalysis. ${ }^{[1]}$ ArMs are constructed by incorporating metallic cofactors into biomolecular scaffolds, which are used to expand the reaction reservoir and explore the novel functions of biomolecules. ${ }^{[2]}$ Beside extensive studies of proteins as chiral scaffolds for ArMs, nucleic acids have recently raised much interest for the

[*] Dr. C. Wang, ${ }^{[+]}$M. Hao, ${ }^{[+]}$Q. Qi, Dr. J. Dang, X. Dong, S. Lv, L. Xiong, H. Gao, Prof. Y. S. Chen

Key Laboratory of Applied Surface and Colloid Chemistry, Ministry of Education, School of Chemistry and Chemical Engineering

Shaanxi Normal University, Xi'an 710119 (China)

E-mail: changhaowang@snnu.edu.cn yschen@snnu.edu.cn

Dr. G. Jia, Prof. C. Li

State Key Laboratory of Catalysis

Dalian Institute of Chemical Physics

Chinese Academy of Sciences, Dalian 116023 (China)

Prof. J. S. Hartig

Department of Chemistry

Konstanz Research School Chemical Biology (KoRS-CB)

University of Konstanz, 78457 Konstanz (Germany)

$\left.{ }^{+}\right]$These authors contributed equally to this work. construction of ArMs because of their diverse tertiary structures, chemical stability, and easy synthetic access. In 2005, Roelfes and Feringa pioneered DNA-based asymmetric catalysis using duplex DNA as scaffold to embed achiral copper(II) complexes to achieve an enantioselective DielsAlder reaction. ${ }^{[3]}$ This concept of DNA-based ArMs has been successively applied to many enantioselective transformations, ${ }^{[4]}$ and in some cases the presence of DNA accelerated the reaction rate. ${ }^{[4,5]}$ Owing to their tunable structures, Gquadruplex DNA-based ArMs have been developed, and their enantioselective catalytic performance is largely dependent on the G-quadruplex structure. ${ }^{[6]}$ In addition, an assembly of G-triplex DNA and $\mathrm{Cu}^{2+}$ ions was built that modestly promotes a Diels-Alder reaction. ${ }^{[7]}$ Since RNA is comparably less stable than DNA, few examples of RNAbased enantioselective catalysis have been described. Jäschke and co-workers have reported the selection of a ribozyme that achieves a Diels-Alder reaction with over $90 \% e e^{\left[{ }^{[8]}\right.}$ Smietana and Arseniyadis have constructed double-stranded RNA hybrid catalysts for Friedel-Crafts (F-C) reactions with modest enantioselectivity. ${ }^{[9]}$ The Hennecke group have discussed why DNA seems to be superior to RNA as a scaffold in nucleic acid based enantioselective catalysis. ${ }^{[10]}$ Although nucleic acid based ArMs successfully transfer the chirality from the nucleic acids to the products and achieve some challenging synthetic reactions, there are still many concerns to be solved, for example, lack of RNA-based ArMs, unclear fine structures, and few explorations on reaction mechanisms. In particular, the current nucleic acid based ArMs contain several tens to several hundreds of (ribo)nucleotides to form the second coordination sphere on a macroscale, thus insight into the precise chiral microenvironment for targeting the metal cofactors is insufficient. Herein, we report an artificial metalloribozyme resulting from incorporation of $\mathrm{Cu}^{2+}$ ions into the scaffold of a cyclic dinucleotide of c-di-AMP that can effectively catalyze enantioselective $\mathrm{F}-\mathrm{C}$ reactions in aqueous media (Scheme 1).

Cyclic dinucleotides (CDNs) are natural cyclic RNA molecules containing two ribonucleotide units and a 12membered ring structure. So far, four canonical 3'-5' linked CDNs (c-di-GMP, c-di-AMP, c-AMP-GMP, c-AMP-UMP) and one non-canonical CDN (2', $3^{\prime}$-c-GAMP) have been discovered in nature ${ }^{[11]}$ and identified as important secondary messengers in the transduction of biological signals and regulation of many cellular processes. ${ }^{[12]}$ These naturally occurring CDNs are easily produced by their specific cyclases and the canonical CDNs are readily synthesized on a large 

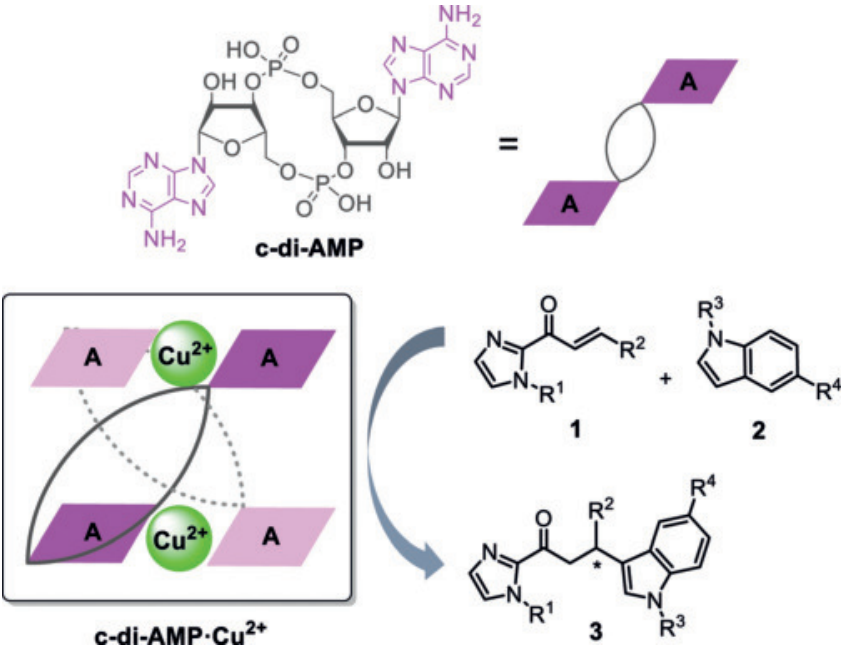

Scheme 1. Schematic representation of enantioselective Friedel-Crafts reactions of $\alpha, \beta$-unsaturated 2-acyl imidazoles (1) and indoles (2) by a cyclic dinucleotide based artificial metalloribozyme (c-di-AMP.C ${ }^{2+}$ ).

scale using a one-pot chemical strategy. ${ }^{[13]}$ Moreover, CDNs are able to form three-dimensional structures. C-di-GMP can fold into diverse structures in the presence of alkali metal ions or aromatic planar intercalators. ${ }^{[14]} \mathrm{Xi}$, Plavec, and co-workers have reported that monomeric $\mathrm{CDNs}$ are stable in U-type structures and are prone to form dimers and tetramers. ${ }^{[15]}$ The Hartig group has demonstrated that some of the formerly unknown CDNs form higher-order structures. ${ }^{[13 b]}$ In addition, a heme analogue embedded into a c-di-GMP octameric scaffold has been shown to mimic the G-quadruplex DNA peroxidase. ${ }^{[16]}$ Hence, the multiple structures available to CDNs raised our interest for using them as chiral scaffolds to construct RNA-based hybrid catalysts.

To investigate the enantioselective catalytic functions of CDNs, an enantioselective F-C reaction of (E)-1-(1-methyl$1 H$-imidazol-2-yl)but-2-en-1-one (1a) and 5-methoxy- $1 H$ indole (2a) was selected as a test reaction. We initially tested c-di-GMP, which can form G-quadruplex structure in the presence $\mathrm{K}^{+}$ions (Figure $\mathrm{S} 1$ in the Supporting Information). However, c-di-GMP alone showed low activity, and nearly racemic products of $\mathbf{3 a}$ were obtained when using either c-di-GMP or c-di-GMP.Cu ${ }^{2+}$ (Table 1, entries 1,2). Since different CDNs displayed distinct profiles in circular dichroism (CD) spectra (Figure S2), we examined c-AMPGMP and c-di-AMP hybrid catalysts. In $\mathrm{K}^{+}$-containing media, c-AMP-GMP. $\mathrm{Cu}^{2+}$ provided 3a with $93 \%$ conversion and $10 \%$ ee (Table 1 , entry 3 ). Surprisingly, c-di-AMP $\cdot \mathrm{Cu}^{2+}$ in the presence of $\mathrm{K}^{+}$ions achieved the $\mathrm{F}-\mathrm{C}$ reaction with a quantitative conversion and a good enantioselectivity of $72 \%$ ee (Table 1, entry 4), thus suggesting that c-di-AMP and $\mathrm{Cu}^{2+}$ ions effectively interact in order to function as a potent hybrid catalyst. Furthermore, we investigated the reaction conditions for c-di-AMP. $\mathrm{Cu}^{2+}$ catalyzed $\mathrm{F}-\mathrm{C}$ reaction by varying the additive, cofactor, temperature, and buffer. Different alkali metal and alkaline earth metal ions as additives show a negative effect on the enantioselectivity, and the highest $85 \%$ ee was obtained with no additives (Table 1, entries 4-7, Tables S1 and S2). This phenomenon is different from $\mathrm{Na}^{+}$- or
Table 1: Enantioselective Friedel-Crafts reaction catalyzed by CDNbased hybrid catalysts. ${ }^{\left[{ }^{[]}\right.}$

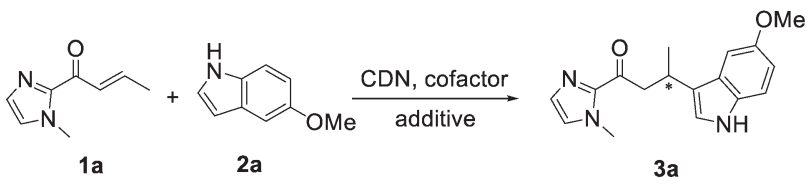

\begin{tabular}{llllll}
\hline Entry & CDN & Cofactor $^{[\mathrm{b}]}$ & Additive & Conversion [\%] & ee [\%] \\
\hline 1 & c-di-GMP & none & $\mathrm{KCl}$ & 20 & 4 \\
2 & c-di-GMP & $\mathrm{Cu}(\mathrm{OTf})_{2}$ & $\mathrm{KCl}$ & 96 & 2 \\
3 & c-AMP- & $\mathrm{Cu}(\mathrm{OTf})_{2}$ & $\mathrm{KCl}$ & 93 & 10 \\
& GMP & & & & \\
4 & c-di-AMP & $\mathrm{Cu}(\mathrm{OTf})_{2}$ & $\mathrm{KCl}$ & $>99$ & 72 \\
5 & c-di-AMP & $\mathrm{Cu}(\mathrm{OTf})_{2}$ & $\mathrm{NaCl}$ & $>99$ & 71 \\
6 & c-di-AMP & $\mathrm{Cu}(\mathrm{OTf})_{2}$ & $\mathrm{MgCl}_{2}$ & $>99$ & 55 \\
7 & c-di-AMP & $\mathrm{Cu}(\mathrm{OTf})_{2}$ & none & $>99$ & 85 \\
8 & c-di-AMP & $\mathrm{Cu}($ bpy $)\left(\mathrm{NO}_{3}\right)_{2}$ & none & $>99$ & 45 \\
9 & c-di-AMP & $\mathrm{Cu}(\mathrm{dmbpy})\left(\mathrm{NO}_{3}\right)_{2}$ & none & $>99$ & 55 \\
10 & c-di-AMP & $\mathrm{Cu}($ phen $)\left(\mathrm{NO}_{3}\right)_{2}$ & none & $>99$ & 59 \\
$11^{\text {[c] }}$ & c-di-AMP & $\mathrm{Cu}(\mathrm{OTf})_{2}$ & none & $>99$ & 90 \\
$12^{\text {[d] }}$ & c-di-AMP & $\mathrm{Cu}(\mathrm{OTf})_{2}$ & none & $>99$ & 60 \\
$13^{\text {[e] }}$ & c-di-AMP & $\mathrm{Cu}(\mathrm{OTf})_{2}$ & none & $>99$ & 87 \\
\hline
\end{tabular}

[a] Reaction conditions: 1 a (1 mM), 2 a $(5 \mathrm{~mm}), \mathrm{CDN}(100 \mu \mathrm{M})$, cofactor $(50 \mu \mathrm{M})$, additive $(100 \mathrm{~mm})$, MOPS buffer $(1 \mathrm{~mL}, 20 \mathrm{~mm}, \mathrm{pH} 6.5), 4^{\circ} \mathrm{C}$, $24 \mathrm{~h}$. The conversion and $e e$ were determined from the crude product by HPLC analysis on a chiral stationary phase. All data were averaged by at least duplicated experiments with the reproducibility of $\pm 5 \%$.

[b] OTf = trifluoromethanesulfonate, bpy $=2,2^{\prime}$-bipyridine, dmbpy $=4,4^{\prime}$ dimethyl-2,2'-bipyridyl, phen =1,10-phenathroline. [c] c-di-AMP $(250 \mu \mathrm{M})$ and $\mathrm{Cu}(\mathrm{OTf})_{2}(50 \mu \mathrm{M})$. [d] Reaction at $37^{\circ} \mathrm{C}$. [e] MES buffer (20 mM, pH 5.5) was used.

$\mathrm{K}^{+}$-promoted G-quadruplex DNA-based enantioselective catalysis. $^{[6 b, c, 17]}$ For the cofactors in the c-di-AMP hybrid catalysts, $\mathrm{Cu}^{2+}$ served as the best cofactor to assist c-di-AMP to achieve enantioselectivity, regardless of the used counter anions (Table S3). However, the introduction of achiral ligands to $\mathrm{c}$-di-AMP. $\mathrm{Cu}^{2+}$ resulted in decreased $e e$ values (Table 1, entries 8-10). Upon increasing the ratio of c-di$\mathrm{AMP} / \mathrm{Cu}^{2+}$, the enantioselectivity gradually increased to $90 \%$ $e e$ with 5:1 c-di-AMP/Cu${ }^{2+}$, however further increasing the cdi-AMP/Cu ${ }^{2+}$ ratio caused no significant changes (Table 1, entry 11, Table $\mathrm{S} 4$ ). When increasing the reaction temperature, a reduced ee was obtained (Table 1, entry 12). Of the buffers 4-morpholinepropanesulfonic acid (MOPS) or 4morpholineethanesulfonic acid (MES), MES (pH 5.5) was selected as the optimal buffer for the following studies (Table 1, entry 13, Table S5).

In order to evaluate the catalytic roles of c-di-AMP and $\mathrm{Cu}^{2+}$ in c-di-AMP. $\mathrm{Cu}^{2+}$, we determined the apparent secondorder rate constant $\left(k_{\text {app }}\right)$ for the $\mathrm{F}-\mathrm{C}$ reaction as previously described. ${ }^{[5 \mathrm{~d}]}$ Compared to the uncatalyzed reaction ( $\left.k_{\text {app,uncat }}\right)$, c-di-AMP slightly inhibited the reaction with $k_{\text {app,c-di-AMP }} /$ $k_{\text {app,uncat }}=0.5 \pm 0.1$, while $\mathrm{Cu}^{2+}$ ions remarkably accelerated the reaction with $k_{\mathrm{app}, \mathrm{Cu} 2+} / k_{\text {app,uncat }}=(1.7 \pm 0.1) \times 10^{2}$ (Figure 1 and Table S6). Once the c-di-AMP and $\mathrm{Cu}^{2+}$ were assembled with a molar ratio of $5: 1, \mathrm{c}$-di-AMP. $\mathrm{Cu}^{2+}(5: 1)$ gave rise to a rate enhancement of 3330-fold compared to the uncatalyzed reaction and 20-fold compared to $\mathrm{Cu}^{2+}$ ions (Figure 1 and Table S6). Compared to c-di-AMP.Cu ${ }^{2+}(5: 1)$, c-di-AMP.Cu ${ }^{2+}$ 


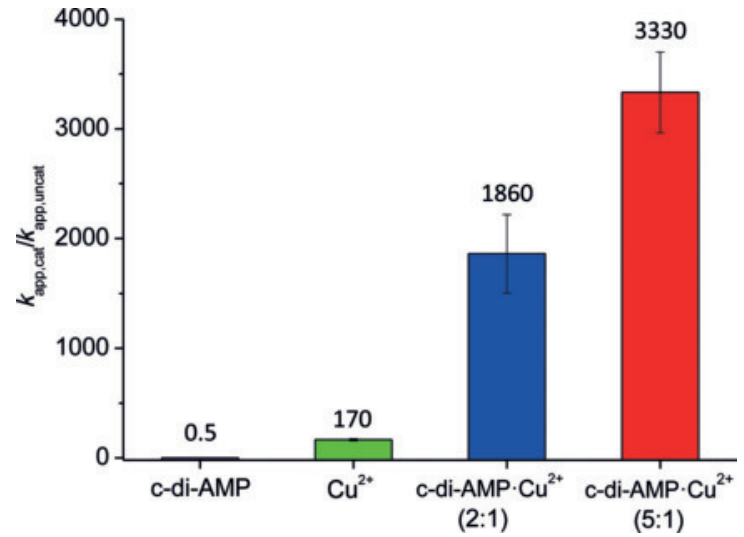

Figure 1. The rate acceleration ( $\left.k_{\text {app,cat }} / k_{\text {app, uncat }}\right)$ for c-di-AMP, $\mathrm{Cu}^{2+}$, and c-di-AMP.C $\mathrm{Cu}^{2+}$. The apparent second-order rate constant $\left(k_{\text {app }}\right)$ was estimated from the initial rate of the $\mathrm{F}-\mathrm{C}$ reaction with $1 \mathrm{a}(0.8 \mathrm{~mm})$ and $2 \mathrm{a}(5 \mathrm{~mm})$ in MES buffer $(1 \mathrm{~mL}, 20 \mathrm{~mm}, \mathrm{pH} 5.5)$ at $4{ }^{\circ} \mathrm{C}$ without catalyst $\left(k_{\text {app,uncat }}\right)$ and with catalysts of c-di-AMP $(100 \mu \mathrm{M}), \mathrm{Cu}^{2+}$ $(50 \mu \mathrm{M})$, c-di-AMP.Cu ${ }^{2+}\left(2: 1,100 \mu \mathrm{M}\right.$ c-di-AMP and $\left.50 \mu \mathrm{M} \mathrm{Cu}^{2+}\right)$, and c-di-AMP.Cu${ }^{2+}\left(5: 1,250 \mu \mathrm{M}\right.$ c-di-AMP and $\left.50 \mu \mathrm{M} \mathrm{Cu}^{2+}\right)$, respectively.

(2:1) caused a slightly lower rate acceleration (Figure 1). These results suggest that c-di-AMP and $\mathrm{Cu}^{2+}$ assemble into a CDN-based artificial metalloribozyme where $\mathrm{Cu}^{2+}$ ions are the main catalytic species and the c-di-AMP provides a chiral secondary coordination sphere. This phenomenon is similar to the descriptions of duplex DNA and G-quadruplex DNA metalloenzymes. ${ }^{[3,6 b]}$

With a c-di-AMP. $\mathrm{Cu}^{2+}$ metalloribozyme in hand, we tested different $\alpha, \beta$-unsaturated 2-acyl imidazoles $(\mathbf{1} \mathbf{a}-\mathbf{i})$ and indoles (2a-d) for enantioselective F-C reactions (Scheme 2). Compared to the reaction of $\mathbf{1 a}\left(\mathrm{R}^{1}=\right.$ methyl) with $\mathbf{2} \mathbf{a}$, the substrates $\mathbf{1 b}$ and $\mathbf{1 c}$, which have larger $\mathrm{R}^{1}$ groups (ethyl, isopropyl), provided decreased ee values (3a vs. 3b,c). Upon changing c-di-AMP. $\mathrm{Cu}^{2+}(2: 1)$ to $\mathrm{c}$-di-AMP. $\mathrm{Cu}^{2+}(5: 1)$, the corresponding enantioselectivity for the synthesis of $\mathbf{3 a} \mathbf{a}-\mathbf{c}$ slightly increased. Upon changing the $\mathrm{R}^{2}$ group in $\alpha, \beta$ unsaturated 2-acyl imidazoles from a methyl to an ethyl or iso-propyl group, no significant differences in the enantioselectivity were observed (3a,d,e) when using either c-diAMP.Cu ${ }^{2+}(2: 1)$ or c-di-AMP.Cu ${ }^{2+}(5: 1)$. Surprisingly, when the $\mathrm{R}^{2}$ group of $\mathbf{1} \mathbf{f}$ was substituted with a tert-butyl moiety, the corresponding $\mathrm{F}-\mathrm{C}$ reactions showed modest conversions but excellent $e e$ values for $\mathbf{3} \mathbf{f}$ of $95 \%$ and $97 \%$ by c-di-AMP. $\mathrm{Cu}^{2+}$ $(2: 1)$ and c-di-AMP.Cu${ }^{2+}(5: 1)$, respectively. When the $\mathrm{R}^{2}$ groups in the substrates were substituted with aromatic moieties, both the reactivity and enantioselectivity were obviously suppressed $(\mathbf{3} \mathbf{g - i})$. Furthermore, different indoles $(\mathbf{2} \mathbf{a}-\mathbf{d})$ were examined for reaction with $\mathbf{1 a}$, and varied $e e$ values were observed $(\mathbf{3} \mathbf{j}-\mathbf{l})$. To examine the synthetic potential of c-di-AMP. $\mathrm{Cu}^{2+}$, we conducted the benchmark reaction on a large scale $(\mathbf{1} \mathbf{a}, 75 \mathrm{mg})$ using c-di-AMP. $\mathrm{Cu}^{2+}$ $(2: 1)$ at $2 \mathrm{~mol} \%$. After gel column chromatography, we obtained 3a at $80 \%$ yield of isolated product and $85 \% e e$, thus indicating that $\mathrm{c}$-di-AMP. $\mathrm{Cu}^{2+}$ could potentially be applied for practical synthesis.

For c-di-AMP (Figure 2a), the possible coordination sites for $\mathrm{Cu}^{2+}$ ions are $\mathrm{N} 1, \mathrm{~N} 3, \mathrm{~N} 6, \mathrm{~N} 7, \mathrm{O}^{2}$, and the phosphate

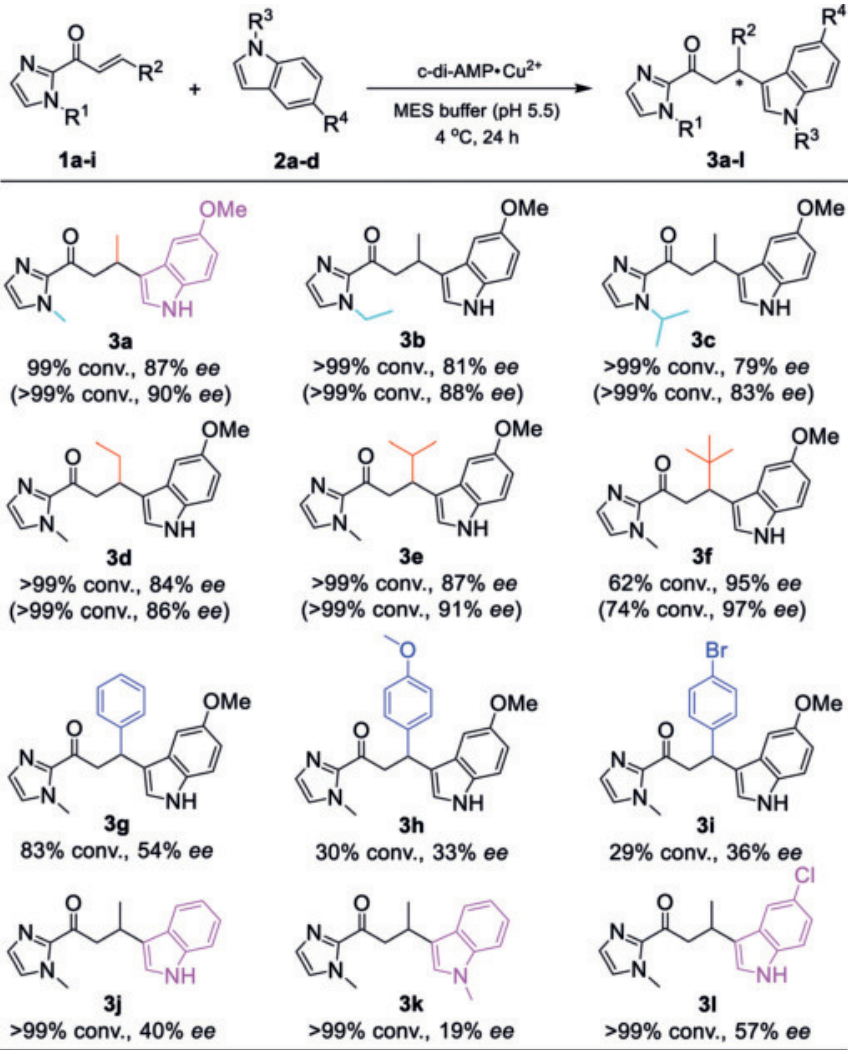

Scheme 2. Substrate scope of the c-di-AMP.Cu ${ }^{2+}$ catalyzed F-C reaction. Reaction conditions: 1 (1 $\mathrm{mm}), 2(5 \mathrm{~mm})$, c-di-AMP $(100 \mu \mathrm{M})$, $\mathrm{Cu}(\mathrm{OTf})_{2}(50 \mu \mathrm{m})$, MES buffer $(1 \mathrm{~mL}, 20 \mathrm{~mm}, \mathrm{pH} \mathrm{5.5}), 4^{\circ} \mathrm{C}, 24 \mathrm{~h}$. The conversion (conv.) of $\mathbf{3}$ a was calculated by HPLC and the conversions of $\mathbf{3} \mathbf{b}-\mathrm{I}$ were estimated by ${ }^{1} \mathrm{H}$ NMR from the crude products. The $e e$ values were determined from the crude products on a chiral HPLC. The data in parentheses represent the corresponding $\mathrm{F}-\mathrm{C}$ reactions using c-di-AMP.Cu ${ }^{2+}(5: 1)$ with $250 \mu \mathrm{M}$ c-di-AMP and $50 \mu \mathrm{M} \mathrm{Cu}{ }^{2+}$ ions. All data show averages of two independent experiments with the reproducibility of conversions at $\pm 5 \%$ and the $e e$ values at $\pm 3 \%$.

oxygen atoms, as described previously for copper/nucleic acid complexes. ${ }^{[18]}$ In an attempt to probe the location of the $\mathrm{Cu}^{2+}$ ion in c-di-AMP. $\mathrm{Cu}^{2+}$, we conducted a series of control experiments for the benchmark F-C reaction with different cdi-AMP analogues (Figure 2b). A cyclic dideoxyribonucleotide of c-di-dAMP instead of c-di-AMP resulted the similar enantioselectivity in the $\mathrm{Cu}^{2+}$-catalyzed $\mathrm{F}-\mathrm{C}$ reaction, thus indicating that $\mathrm{O}^{\prime}$ in c-di-AMP is not a primary binding site for the $\mathrm{Cu}^{2+}$ ions. Compared to c-di-AMP, the CDNs containing just one AMP moiety (c-AMP-CMP, c-AMPUMP, and c-AMP-GMP) gave metalloribozymes that yielded decreased $e e$ values, and c-di-GMP provided a very low $e e$, thus showing that $\mathrm{Cu}^{2+}$ ions could be specifically targeted by adenine in CDNs. Moreover, the non-cyclic form of c-di-AMP (3'-pApA), 3',5'-cyclic AMP, AMP, and adenine gave nearly racemic products in $\mathrm{Cu}^{2+}$-catalyzed $\mathrm{F}-\mathrm{C}$ reactions. The above results suggest that the 12-membered cyclic scaffold and two adenines are indispensable for $\mathrm{CDN}$-based metalloribozymes to exert highly enantioselective catalysis.

To investigate the interaction between c-di-AMP and $\mathrm{Cu}^{2+}$ ions, several biophysical techniques were employed. 


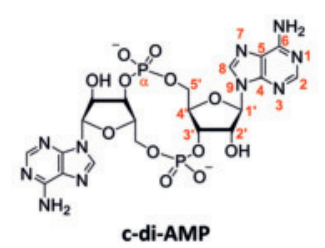

b

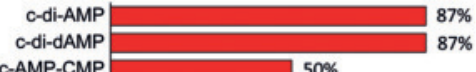

C-AMP-CMP $50 \%$

C-AMP-UMP $38 \%$

C-AMP-GMP $11 \%$

c-di-GMP $4 \%$

3'-PAPA $2 \%$

3', 5'-cyclic AMP $<1 \%$

AMP $<1 \%$

Adenine $<1 \%$
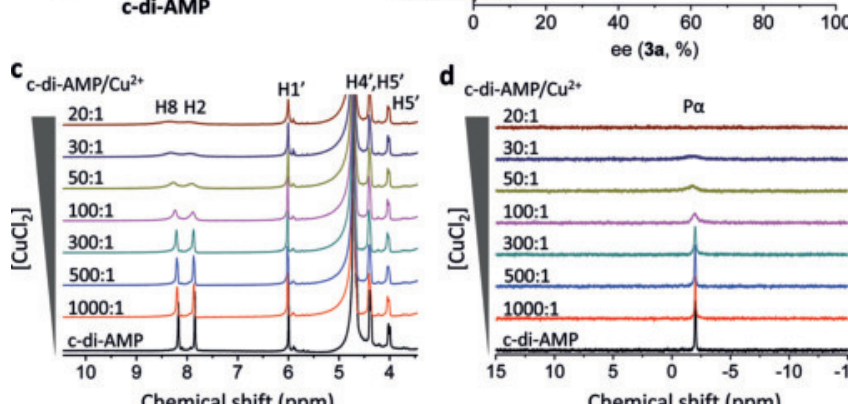

d

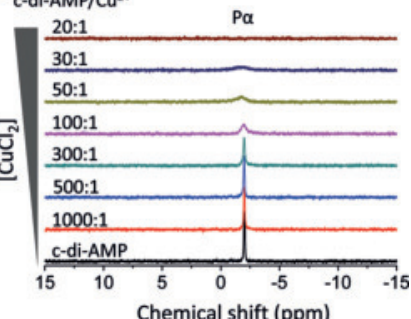

Figure 2. a) Chemical structure of c-di-AMP. b) Control experiments for the $\mathrm{Cu}^{2+}$-catalyzed F-C reaction with different c-di-AMP analogues. Reaction conditions: 1 a (1 mM), 2a (5 mM), c-di-AMP analogue $(100 \mu \mathrm{M}), \mathrm{Cu}(\mathrm{OTf})_{2}(50 \mu \mathrm{M})$, MES buffer $(1 \mathrm{~mL}, 20 \mathrm{~mm}, \mathrm{pH} 5.5), 4^{\circ} \mathrm{C}$, $24 \mathrm{~h}$. All the control experiments were at conversions beyond $98 \%$. c) ${ }^{1} \mathrm{H}$ NMR and d) ${ }^{31} \mathrm{P}$ NMR titrations of c-di-AMP $(9.4 \mathrm{~mm}$ ) with varying concentrations of $\mathrm{CuCl}_{2}(9.4-470 \mu \mathrm{M})$ in $\mathrm{D}_{2} \mathrm{O}$.

Upon increasing the amount of $\mathrm{Cu}^{2+}$ ions, UV/Vis and CD spectra of the c-di-AMP showed slight concentration-dependent behaviors (Figure S13), thus indicating that c-di-AMP and $\mathrm{Cu}^{2+}$ ions do indeed interact. The binding affinity between c-di-AMP and $\mathrm{Cu}^{2+}$ ions was quantitatively analyzed, with an apparent dissociation constant $\left(K_{\mathrm{d}}\right)$ of $646 \pm$ $32 \mu \mathrm{M}$ obtained by UV titration experiments (Figure S16). Nuclear magnetic resonance (NMR) was also used although the $\mathrm{Cu}^{2+}$ ion is a paramagnetic species. Compared to ${ }^{1} \mathrm{H}$ NMR of c-di-AMP, titration with $\mathrm{Cu}^{2+}$ ions broadened and downfield-shifted the signals of $\mathrm{H} 8$ and $\mathrm{H} 2$, yet other protons remained almost unchanged (Figure $2 \mathrm{c}$ ). These results suggest that the magnetic environment around $\mathrm{H} 8$ and $\mathrm{H} 2$ of $\mathrm{c}$ di-AMP is disturbed upon the addition of $\mathrm{Cu}^{2+}$ ions, leading us to assume that $\mathrm{N} 1, \mathrm{~N} 3$, and $\mathrm{N} 7$ are likely the binding sites of $\mathrm{Cu}^{2+}$ ions. Moreover, the addition of $\mathrm{Cu}^{2+}$ ions to c-di-AMP caused broadening and a small downfield shift for the P $\alpha$ signal (Figure 2d), thus indicating that phosphates in c-diAMP are likely another binding site of $\mathrm{Cu}^{2+}$ ions. Based on the c-di-AMP analogue experiments and biophysical characterization, we conclude that the $\mathrm{Cu}^{2+}$ ions most likely interact with N7, N3, N1, and phosphate oxygen atoms in c-di-AMP to assemble a CDN-based metalloribozyme.

To clarify the structure of c-di-AMP. $\mathrm{Cu}^{2+}$ and explore a plausible reaction mechanism, density function theory (DFT) calculations were conducted. In the experimental study, the absolute configuration of $\mathbf{3}$ a obtained from the F-C reaction catalyzed by c-di-AMP. $\mathrm{Cu}^{2+}$ was confirmed as $R$ by comparison of the HPLC trace and crystal analysis to those reported for $(R)-\mathbf{3 a}$ (Figure $3 \mathrm{a}$ and Figure S17). ${ }^{[19]}$ In DFT calculations, c-di-AMP is stable in a U-type scaffold with intramolecular $\pi-\pi$ stacking between two adenines (Figure $3 \mathrm{~b}$ ), which is consistent with recent reports. ${ }^{[15]}$ Once the
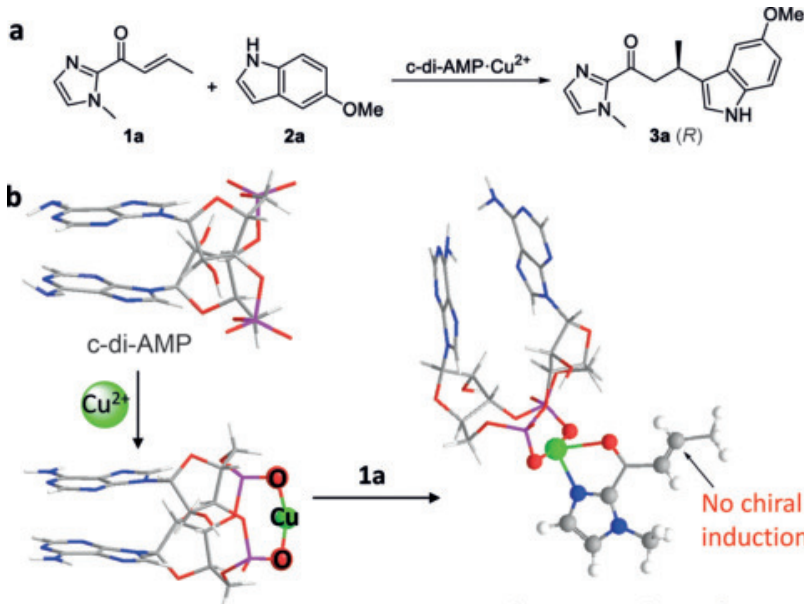

c-di-AMP. $\mathrm{Cu}^{2+}$ (momomer) 1 dimerization

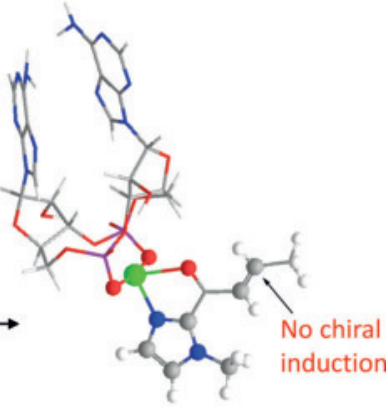

The intermediate of c-di-AMP. $\mathrm{Cu}^{2+}$ (momomer) and 1a

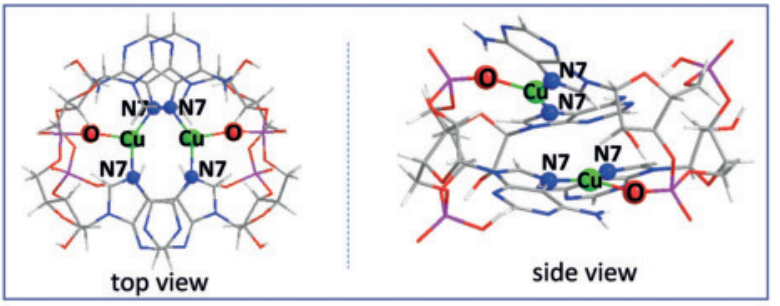

c-di-AMP.Cu ${ }^{2+}$ (dimer)

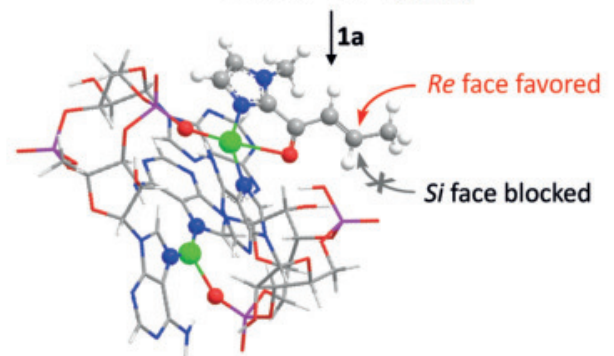

The intermediate of c-di-AMP.Cu ${ }^{2+}$ (dimer) and $\mathbf{1 a}$

Figure 3. a) c-di-AMP.Cu $\mathrm{Cu}^{2+}$ catalyzed F-C reaction of $\mathbf{1}$ a and $\mathbf{2}$ a yields 3 a with the $R$ configuration. b) DFT calculations of the optimized conformations of c-di-AMP, c-di-AMP. $\mathrm{Cu}^{2+}$ and the intermediates of cdi-AMP.Cu ${ }^{2+}$ and $1 \mathrm{a}$

$\mathrm{Cu}^{2+}$ ions are added, two possible c-di-AMP $\cdot \mathrm{Cu}^{2+}$ monomers were obtained (Figure S18). The more stable one has the $\mathrm{Cu}^{2+}$ ion binding to two oxygen atoms from two phosphates, but interaction of this c-di-AMP. $\mathrm{Cu}^{2+}$ monomer with $\mathbf{1}$ a provides an intermediate with no further chiral induction (Figure $3 \mathrm{~b}$ ). Another c-di-AMP. $\mathrm{Cu}^{2+}$ monomer is less stable and yields the product 3a with the $S$ configuration that conflicts with the experimental result (Figure S18). Intriguingly, the stable c-di$\mathrm{AMP} \cdot \mathrm{Cu}^{2+}$ monomer tends to rearrange to a more stable dimer with intermolecular $\pi-\pi$ stacking of adenines (Figure $3 \mathrm{~b}$ ) in an exothermic process with a binding energy of $-85.4 \mathrm{kcal} \mathrm{mol}^{-1}$. In this c-di-AMP. $\mathrm{Cu}^{2+}$ dimer, two $\mathrm{Cu}^{2+}$ ions are locating equivalently in the center of two adenine-adenine planes and each $\mathrm{Cu}^{2+}$ ion is trapped by two N7 nitrogen atoms from different c-di-AMP residues and one nearby phosphate oxygen atom (Figure $3 \mathrm{~b}$ ). Importantly, the addition of $\mathbf{1 a}$ to 
the c-di-AMP. $\mathrm{Cu}^{2+}$ dimer forms an intermediate that allows 2 a to preferentially attack from the $R e$ face rather than $S i$ face (Figure $3 \mathrm{~b}$ ), leading to the product $\mathbf{3 a}$ with the $R$ configuration, which is in accordance with the experimental result. Based on the above experimental data and the DFT calculations, a plausible fine structure of c-di-AMP. $\mathrm{Cu}^{2+}$ metalloribozyme is a dimeric form where the $\mathrm{Cu}^{2+}$ ion is located in the center of an A-A plane through binding to two N7 nitrogen atoms and one phosphate oxygen atom.

In conclusion, we found that c-di-AMP and $\mathrm{Cu}^{2+}$ ions assemble into a CDN-based artificial metalloribozyme that shows quantitative conversions and up to $97 \%$ ee in enantioselective F-C reactions. The resulting c-di-AMP. $\mathrm{Cu}^{2+}$ provides a significant rate acceleration in comparison to $\mathrm{Cu}^{2+}$ ions. The enantioselective catalytic performance of c-di$\mathrm{AMP} \cdot \mathrm{Cu}^{2+}$ is largely dependent on the 12 -membered cyclic scaffold and the two adenine moieties. Based on biophysical characterizations and DFT calculations, the structure of c-diAMP. $\mathrm{Cu}^{2+}$ is proposed as a dimeric complex where the $\mathrm{Cu}^{2+}$ ion is likely located in the A-A plane through coordination with two N7 atoms and one phosphate oxygen. This study suggests that the CDNs serve as powerful scaffolds in order to construct artificial metalloribozymes, and their (enantio)selective performance could be tuned by alteration of the nucleobases. Given their ability to bind metal ions and catalyze the described reactions, we anticipate that cyclic dinucleotides could be able to catalyze other challenging organic transformations. In addition, we speculate that such small, naturally occurring cyclic RNAs may have been able to catalyze metabolic reactions in an early RNA world scenario.

\section{Acknowledgements}

We thank Prof. Yu Fang, Prof. Dong Xue, Prof. Yan Jin, Prof. Xiaodong Shi and Prof. Kaiqiang Liu for helpful discussions. We are grateful for the financial supports of the National Natural Science Foundation of China (Nos. 21703132, 21773149, 21273142), the Natural Science Foundation of Shaanxi Province of China (2019JQ161), and the Fundamental Research Funds for the Central Universities (GK201802001).

\section{Conflict of interest}

The authors declare no conflict of interest.

Keywords: artificial metalloribozymes - c-di-AMP . cyclic dinucleotides homogeneous catalysis . nucleic acid based catalysts

[1] a) Y. Lu, N. Yeung, N. Sieracki, N. M. Marshall, Nature 2009, 460, $855-862$; b) N. J. Turner, Nat. Chem. Biol. 2009, 5, 568-574; c) A. Pordea, T. R. Ward, Synlett 2009, 3225-3236; d) T. Heinisch, T. R. Ward, Curr. Opin. Chem. Biol. 2010, 14, $184-$
199; e) O. Pàmies, M. Dieguez, J.-E. Backvall, Adv. Synth. Catal. 2015, 357, 1567-1586; f) J. F. Hartwig, T. R. Ward, Acc. Chem. Res. 2019, 52, 1145-1145.

[2] a) F. Schwizer, Y. Okamoto, T. Heinisch, Y. Gu, M. M. Pellizzoni, V. Lebrun, R. Reuter, V. Kohler, J. C. Lewis, T. R. Ward, Chem. Rev. 2018, 118, 142-231; b) S. N. Natoli, J. F. Hartwig, Acc. Chem. Res. 2019, 52, 326-335; c) M. T. Reetz, Acc. Chem. Res. 2019, 52, 336-344; d) A. D. Liang, J. Serrano-Plana, R. L. Peterson, T. R. Ward, Acc. Chem. Res. 2019, 52, 585-595; e) C. Zeymer, D. Hilvert, Annu. Rev. Biochem. 2018, 87, 131-157; f) F. Nastri, M. Chino, O. Maglio, A. Bhagi-Damodaran, Y. Lu, A. Lombardi, Chem. Soc. Rev. 2016, 45, 5020-5054; g) J. Bos, G. Roelfes, Curr. Opin. Chem. Biol. 2014, 19, 135-143; h) C. M. Thomas, T. R. Ward, Chem. Soc. Rev. 2005, 34, 337-346.

[3] G. Roelfes, B. L. Feringa, Angew. Chem. Int. Ed. 2005, 44, 3230 3232; Angew. Chem. 2005, 117, 3294-3296.

[4] a) D. Coquière, B. L. Feringa, G. Roelfes, Angew. Chem. Int. Ed. 2007, 46, 9308-9311; Angew. Chem. 2007, 119, 9468 -9471; b) N. Shibata, H. Yasui, S. Nakamura, T. Toru, Synlett 2007, $1153-$ 1157; c) P. Fournier, R. Fiammengo, A. Jäschke, Angew. Chem. Int. Ed. 2009, 48, 4426-4429; Angew. Chem. 2009, 121, 44904493 ; d) A. J. Boersma, R. P. Megens, B. L. Feringa, G. Roelfes, Chem. Soc. Rev. 2010, 39, 2083-2092; e) A. J. Boersma, D. Coquière, D. Geerdink, F. Rosati, B. L. Feringa, G. Roelfes, Nat. Chem. 2010, 2, 991-995; f) J. Oelerich, G. Roelfes, Chem. Sci. 2013, 4, 2013-2017; g) A. Rioz-Martínez, J. Oelerich, N. Segaud, G. Roelfes, Angew. Chem. Int. Ed. 2016, 55, 14136-14140; Angew. Chem. 2016, 128, 14342-14346.

[5] a) A. J. Boersma, J. E. Klijn, B. L. Feringa, G. Roelfes, J. Am. Chem. Soc. 2008, 130, 11783-11790; b) A. J. Boersma, B. L. Feringa, G. Roelfes, Angew. Chem. Int. Ed. 2009, 48, 3346-3348; Angew. Chem. 2009, 121, 3396-3398; c) E. W. Dijk, A. J. Boersma, B. L. Feringa, G. Roelfes, Org. Biomol. Chem. 2010, 8, 3868 -3873; d) A. García-Fernández, R. P. Megens, L. Villarino, G. Roelfes, J. Am. Chem. Soc. 2016, 138, 16308-16314.

[6] a) S. Roe, D. J. Ritson, T. Garner, M. Searle, J. E. Moses, Chem. Commun. 2010, 46, 4309-4311; b) C. Wang, G. Jia, J. Zhou, Y. Li, Y. Liu, S. Lu, C. Li, Angew. Chem. Int. Ed. 2012, 51, $9352-$ 9355; Angew. Chem. 2012, 124, 9486-9489; c) C. Wang, Y. Li, G. Jia, Y. Liu, S. Lu, C. Li, Chem. Commun. 2012, 48, 6232-6234; d) M. Wilking, U. Hennecke, Org. Biomol. Chem. 2013, 11, 6940-6945; e) S. Dey, A. Jäschke, Angew. Chem. Int. Ed. 2015, 54, 11279-11282; Angew. Chem. 2015, 127, 11432-11436; f) Y. Li, M. Cheng, J. Hao, C. Wang, G. Jia, C. Li, Chem. Sci. 2015, 6, 5578-5585; g) M. Cheng, Y. Li, J. Zhou, G. Jia, S.-M. Lu, Y. Yang, C. Li, Chem. Commun. 2016, 52, 9644-9647; h) S. Dey, C. L. Rühl, A. Jäschke, Chem. Eur. J. 2017, 23, 12162-12170.

[7] X. Xu, W. Mao, F. Lin, J. Hu, Z. He, X. Weng, C.-J. Wang, X. Zhou, Catal. Commun. 2016, 74, 16-18.

[8] B. Seelig, S. Keiper, F. Stuhlmann, A. Jäschke, Angew. Chem. Int. Ed. 2000, 39, 4576-4579; Angew. Chem. 2000, 112, 4764-4768.

[9] N. Duchemin, E. Benedetti, L. Bethge, S. Vonhoff, S. Klussmann, J.-J. Vasseur, J. Cossy, M. Smietana, S. Arseniyadis, Chem. Commun. 2016, 52, 8604-8607.

[10] J. J. Marek, U. Hennecke, Chem. Eur. J. 2017, 23, 6009-6013.

[11] a) P. Ross, H. Weinhouse, Y. Aloni, D. Michaeli, P. Weinbergerohana, R. Mayer, S. Braun, E. Devroom, G. A. Vandermarel, J. H. Vanboom, M. Benziman, Nature 1987, 325, 279-281; b) G. Witte, S. Hartung, K. Büttner, K. P. Hopfner, Mol. Cell 2008, 30, 167-178; c) B. W. Davies, R. W. Bogard, T. S. Young, J. J. Mekalanos, Cell 2012, 149, 358-370; d) P. Gao, M. Ascano, Y. Wu, W. Barchet, B. L. Gaffney, T. Zillinger, A. A. Serganov, Y. Liu, R. A. Jones, G. Hartmann, T. Tuschl, D. J. Patel, Cell 2013, 153, 1094-1107; e) A. T. Whiteley, J. B. Eaglesham, C. C. de Oliveira Mann, B. R. Morehouse, B. Lowey, E. A. Nieminen, O. Danilchanka, D. S. King, A. S. Y. Lee, J. J. Mekalanos, P. J. Kranzusch, Nature 2019, 567, 194-199. 
[12] a) R. Hengge, Nat. Rev. Microbiol. 2009, 7, 263-273; b) R. M. Corrigan, A. Gründling, Nat. Rev. Microbiol. 2013, 11, 513-524; c) L. Sun, J. Wu, F. Du, X. Chen, Z. J. Chen, Science 2013, 339, 786-791; d) J. Wu, L. Sun, X. Chen, F. Du, H. Shi, C. Chen, Z. J. Chen, Science 2013, 339, 826-830.

[13] a) B. L. Gaffney, E. Veliath, J. Zhao, R. A. Jones, Org. Lett. 2010, 12, 3269-3271; b) C. Wang, M. Sinn, J. Stifel, A. C. Heiler, A. Sommershof, J. S. Hartig, J. Am. Chem. Soc. 2017, 139, $16154-$ 16160.

[14] a) Z. Y. Zhang, B. L. Gaffney, R. A. Jones, J. Am. Chem. Soc. 2004, 126, 16700-16701; b) Z. Y. Zhang, S. Kim, B. L. Gaffney, R. A. Jones, J. Am. Chem. Soc. 2006, 128, 7015-7024; c) S. Nakayama, I. Kelsey, J. Wang, K. Roelofs, B. Stefane, Y. Luo, V. T. Lee, H. O. Sintim, J. Am. Chem. Soc. 2011, 133, 4856-4864; d) S. Nakayama, I. Kelsey, J. Wang, H. O. Sintim, Chem. Commun. 2011, 47, 4766-4768; e) M. Gentner, M. G. Allan, F.
Zaehringer, T. Schirmer, S. Grzesiek, J. Am. Chem. Soc. 2012, 134, 1019-1029.

[15] B. Wang, Z. Wang, U. Javornik, Z. Xi, J. Plavec, Sci. Rep. 2017, 7, 16550.

[16] B. T. Roembke, J. Wang, S. Nakayama, J. Zhou, H. O. Sintim, RSC Adv. 2013, 3, 6305-6310.

[17] C. Wang, G. Jia, Y. Li, S. Zhang, C. Li, Chem. Commun. 2013, 49, $11161-11163$.

[18] A. Erxleben, Coord. Chem. Rev. 2018, 360, 92-121.

[19] H. Huo, C. Fu, K. Harms, E. Meggers, J. Am. Chem. Soc. 2014, $136,2990-2993$. 